\title{
A Neuronal-specific Mammalian Homolog of the Drosophila Retinal Degeneration B Gene with Expression Restricted to the Retina and Dentate Gyrus
}

\author{
Changwan Lu, ${ }^{1}$ Thomas S. Vihtelic, ${ }^{2}$ David R. Hyde, ${ }^{2}$ and Tiansen Li ${ }^{1}$ \\ ${ }^{1}$ Berman-Gund Laboratory for the Study of Retinal Degenerations, Harvard Medical School, Massachusetts Eye and Ear \\ Infirmary, Boston, Massachusetts 02114, and 2Department of Biological Sciences, University of Notre Dame, Notre \\ Dame, Indiana 46556
}

\begin{abstract}
Mutations in the Drosophila retinal degeneration B $(r d g B)$ gene cause a rapid loss of the electrophysiological light response and subsequent light-enhanced photoreceptor degeneration. The $r d g B$ gene encodes a protein with an N-terminal phosphatidylinositol transfer protein domain, a large C-terminal segment, and several hydrophobic regions thought to multiply span the subrhabdomeric cisternal membrane. A mammalian $r d g B$ homolog ( $m$-rdgB1) was previously identified and shown to exhibit widespread tissue distribution and functionally rescue the Drosophila rdgB mutant phenotypes. We describe a second mammalian $r d g B$ homolog $(m-r d g B 2)$ that possesses $46 \%$ amino acid identity to Drosophila RdgB and $56 \%$ identity to M-RdgB1. M-RdgB2 possesses a neuronal-specific expression pattern, with high levels in the retina and the dentate gyrus
\end{abstract}

The Drosophila retinal degeneration B $(r d g B)$ gene was discovered in three independent screens for mutants that exhibited either abnormal photoreceptor physiology or retinal degeneration (Hotta and Benzer, 1969; Pak et al., 1970; Heisenberg, 1971). The $r d g B$ mutant exhibits a defective light response as measured by the electroretinogram (ERG) and subsequently undergoes a lightenhanced photoreceptor degeneration (Harris and Stark, 1977). The $r d g B$ mutant flies produce an initial light response of near wild-type amplitude but require prolonged dark recovery times to regenerate any subsequent light response (Milligan et al., 1997). Within a day, $r d g B$ mutants lose their light response entirely. This suggests the $r d g B$ mutation disrupts an aspect of the visual transduction cascade, which is mediated by phospholipase $\mathrm{C}$ hydrolysis of phosphatidylinositol $(4,5)$-bisphosphate $\left(\mathrm{PIP}_{2}\right)$ (Ranganathan et al., 1995). Consistent with this hypothesis, mutations in several genes encoding phototransduction components, such as ninaE (rhodopsin), norpA (phospholipase C), or trp (light-activated $\mathrm{Ca}^{2+}$ channel), suppress $r d g B$-dependent photoreceptor degeneration (Harris and Stark, 1977; Paetkau et al., 1999).

\footnotetext{
Received March 11, 1999; revised June 11, 1999; accepted June 17, 1999.

This work was supported by National Institute of Health Grants EY10309 (T.L.) and EY08058 (D.R.H.), the Foundation Fighting Blindness (T.L.), a career development award from Research to Prevent Blindness (T.L.), and a postdoctoral fellowship from the Fight For Sight research division of Prevent Blindness America (C.L.). We thank Jingzi Shang for initial sequencing analysis, Yan Cheng for Drosophila embryo injections and histological sectioning, and Raya Elagina for ERG analysis.

Correspondence should be addressed to Dr. Tiansen Li, Berman-Gund Laboratory for the Study of Retinal Degenerations, Massachusetts Eye and Ear Infirmary, 243 Charles Street, Boston, MA 02114.

Copyright (C) 1999 Society for Neuroscience 0270-6474/99/197317-09\$05.00/0
}

mossy fibers and dendritic field. Using M-RdgB2-specific antibodies and subcellular fractionation, we demonstrate that $\mathrm{M}-\mathrm{RdgB} 2$ is not an integral membrane protein but is stably associated with a particulate fraction through protein-protein interactions. Although transgenic expression of M-RdgB2 in $r d g B 2$ null mutant flies suppressed the retinal degeneration, it failed to fully restore the electrophysiological light response. Because transgenic expression of M-RdgB2 does not restore the wild-type phenotype to $r d g B 2$ mutant flies to the same extent as $\mathrm{M}-\mathrm{RdgB1}$, functional differences likely exist between the two M-RdgB homologs.

Key words: rdgB; retinal degeneration; PITP; dentate gyrus; hippocampus; autism

The $r d g B$ gene encodes a $160 \mathrm{kDa}$ protein that possesses a calcium-binding domain, six hydrophobic segments purported to be membrane spanning regions, and an N-terminal 281 amino acids that are greater than $40 \%$ identical to rat brain phosphatidylinositol transfer protein (PITP) (Vihtelic et al., 1991, 1993). PITPs are $30-35 \mathrm{kDa}$ soluble proteins operationally defined by their ability to transfer PI and phosphatidylcholine (PC) between membrane compartments in vitro (Bankaitis et al., 1990; Cleves et al., 1991; Wirtz, 1991). A soluble form of the RdgB PITP domain possessed PI and PC transfer activity in vitro and rescued the rdgB2 mutant phenotypes in vivo (Vihtelic et al., 1993; Milligan et al., 1997). Therefore, RdgB represents a novel PITP with an extended hydrophobic $\mathrm{C}$ terminus. However, PI transfer activity does not fully account for the function of $\mathrm{RdgB}$, because neither the soluble rat brain PITP $\alpha$ nor a hybrid RdgB protein in which the PITP domain was replaced by the rat brain PITP $\alpha$ rescued the $r d g B$ mutant phenotypes (Milligan et al., 1997).

Recently, a mammalian $r d g B(m-r d g B)$ homolog was identified and characterized (Aikawa et al., 1997; Chang et al., 1997; Guo and Yu, 1997; Rubboli et al., 1997). Similar to the Drosophila protein, mammalian RdgB possesses an N-terminal PITP domain and multiple hydrophobic segments. The Drosophila and mammalian homologs are also functionally related, because transgenic expression of M-RdgB1 fully restores the ERG light response and prevents retinal degeneration in $r d g B$ mutant flies (Chang et al., 1997). The remarkable structural and functional conservation has led to the suggestion that the PI cycle may participate in some aspect of mammalian photoreceptor physiology through M-RdgB1 (Chang et al., 1997). We describe the characterization 
of a second mammalian $r d g B$ homolog that is selectively expressed in the dentate gyrus of the hippocampus and the retina. We show that this mammalian homolog, M-RdgB2, also rescues photoreceptor degeneration in $r d g B$ mutant flies, without fully restoring the ERG light response. Contrary to our expectation, $\mathrm{M}-\mathrm{RdgB} 2$ does not behave as an integral membrane protein in subcellular fractionation assays.

\section{MATERIALS AND METHODS}

cDNA cloning. Poly $\left(\mathrm{A}^{+}\right)$mRNA from adult $\mathrm{C} 57 \mathrm{BL} / 6 \mathrm{~J}$ mouse retinas (Charles River Laboratories, Wilmington, MA) was used to construct a cDNA library in the Uni-ZAP XR vector (Stratagene, La Jolla, CA). The library was screened with a DNA probe corresponding to the PITP domain of human $r d g B$ (Guo and Yu, 1997). The identities of isolated clones were analyzed by DNA sequencing.

Northern analysis. Poly $\left(\mathrm{A}^{+}\right)$mRNAs from mouse retina, cerebrum, cerebellum, and heart were separated by denaturing agarose gel electrophoresis $(0.5 \mu \mathrm{g} /$ lane of RNA), transferred to nitrocellulose, and hybridized overnight $\left(60^{\circ} \mathrm{C} ; 6 \times \mathrm{SSC}, 5 \times\right.$ Denhardt's, $0.1 \%$ SDS, and $10 \mathrm{mg} / \mathrm{ml}$ salmon sperm DNA) to a ${ }^{32} \mathrm{P}$-labeled $m-r d g B 2$ DNA probe corresponding to the entire coding sequence. The final stringency wash was in $0.2 \times$ SSC at $60^{\circ} \mathrm{C}$. To assess gel-loading equivalency, the membrane was stripped and reprobed with a $700 \mathrm{bp}$ mouse $\beta$-actin DNA fragment. Northern analysis was also performed on multiple tissue blots containing $2 \mu \mathrm{g}$ of poly $\left(\mathrm{A}^{+}\right)$mRNA each from mouse heart, brain, spleen, lung, liver, skeletal muscle, kidney, and testis (Clontech, Palo Alto, CA).

In situ $m R N A$ hybridization. Mouse eye and brain tissues were fixed in $4 \%$ formaldehyde-PBS, $\mathrm{pH} \mathrm{7.0,} \mathrm{for} 2 \mathrm{hr}$, and the anterior segments and lens were removed. After sequential soaking in 10 and $30 \%$ sucrose, tissues were quick frozen in OCT and sectioned at $12 \mu \mathrm{m}$. Sections were treated sequentially in $0.25 \%$ Triton X-100-PBS, proteinase $\mathrm{K}(10 \mu \mathrm{g} /$ $\mathrm{ml} ; 10 \mathrm{~min}$ at room temperature), and $2 \times \mathrm{SSC}$, dehydrated in a graded ethanol series, and prehybridized for $3 \mathrm{hr}$ at $60^{\circ} \mathrm{C}(50 \%$ formamide, $5 \times$ SSC, $2 \times$ Denhardt's, 5 mm EDTA, 0.1\% CHAPS, and $200 \mu \mathrm{g} / \mathrm{ml}$ yeast tRNA). Digoxigenin-labeled sense and antisense $m$-rdgB2 RNA probes spanning the entire coding region were generated using a Genius 4 digoxigenin RNA labeling kit (Boehringer Mannheim, Indianapolis, IN) and alkaline hydrolyzed to an average size of $400 \mathrm{bp}$. The probes (1 $\mathrm{ng} / \mu \mathrm{l})$ were hybridized for $36-40 \mathrm{hr}$ at $60^{\circ} \mathrm{C}$. Sections were washed sequentially in $2 \times \mathrm{SSC}, 1 \times \mathrm{SSC}$, and $0.5 \times \mathrm{SSC}(10 \mathrm{~min}$ each at room temperature), followed by $0.1 \times$ SSC and $0.1 \times$ SSC $-20 \%$ formamide $(1$ $\mathrm{hr}$ each at $\left.55^{\circ} \mathrm{C}\right)$. Sections were treated with RNase A $(20 \mu \mathrm{g} / \mathrm{ml})$ for 30 $\min$ at $37^{\circ} \mathrm{C}$. Detection of the digoxigenin-labeled probe using alkaline phosphatase-conjugated anti-digoxigenin antibodies was performed per the manufacturer's instructions.

Antibodies. Two segments in the $m-r d g B 2$ coding sequence corresponding to codons 233-460 (a2) and codons 1114-1281 (a3) were selected for generating polyclonal antibodies based on their lack of similarity with known proteins and predicted hydrophilicity. DNA fragments were subcloned into the pET28 vector (Novagen, Madison, WI) at the Eco RI site, and the fusion proteins were expressed and affinity purified from Escherichia coli BL21pLysS using His-Bind resin according to the manufacturer's protocol (Novagen). Antibodies were produced in chicken (a2 fusion protein; Cocalico Biologicals, Inc., Reamstown, PA) or rabbit (a3 fusion protein; Zymed, South San Francisco, CA). Specific antibodies were affinity purified from rabbit antiserum or total chicken IgY using the cognate antigens immobilized to agarose beads (AminoLink Plus Immobilization kit; Pierce, Rockford, IL). Antibody specificity was demonstrated by blocking with competing antigens and by lack of crossreactivity against $\mathrm{M}-\mathrm{RdgB} 1$. Both the $\mathrm{a} 2$ and $\mathrm{a} 3$ antibodies detected a single polypeptide in retinal and brain extracts on immunoblots and identical patterns in tissue sections. Because the a3 antiserum gave a consistently better signal-to-noise ratio, it was used for all subsequent analyses.

Immunocytochemistry. Tissue was fixed in $4 \%$ formaldehyde for 30 min, frozen sectioned $(12 \mu \mathrm{m})$, blocked in $5 \%$ normal rabbit or goat serum in PBS for $1 \mathrm{hr}$, and incubated with anti-a2 IgY (1:2000) or anti-a3 $\operatorname{IgG}(1: 4000)$ for $4 \mathrm{hr}$ to overnight. After washing in PBS, sections were incubated in secondary antibodies: either Cy3-conjugated rabbit antichicken IgY or goat anti-rabbit IgG (Jackson ImmunoResearch, West Grove, PA) for $1 \mathrm{hr}$. Preimmune serum or IgY were used as negative controls.
Chromosomal mapping. The $m-r d g B 2$ gene was mapped by PCR using an interspecific backcross mouse DNA panel from The Jackson Laboratory (Bar Harbor, ME) (Rowe et al., 1994). A primer pair flanking a 6.8 kb DNA segment from exon 1 to intron 3 (5'-AGAACCGGCCCTACACAGACGGCCC-3' and 5'-GTGTACCACTGAGCCTGGTTC$3^{\prime}$ ) was used for first-round PCR amplification, followed by nested PCR with primers 5'-TGGCGGCTCCGGGCAATACA-3' and 5'GGATTCAACCTCAGGTGCAC- $3^{\prime}$. The $6.8 \mathrm{~kb}$ product was digested with the restriction enzyme $T a q \mathrm{I}$ and electrophoresed through a $1 \%$ agarose gel. A number of bands were identical between the parental strains, but two unique bands of 1.5 and $1.4 \mathrm{~kb}$ were found only in one parental strain, whereas the other strain had a $2.9 \mathrm{~kb}$ band. This restriction site polymorphism allowed the typing of crossovers at this locus. Chromosomal location was assigned by The Jackson Laboratory.

Subcellular fractionation of $M-R d g B 2$. One mouse brain or 10 retinas, freshly isolated, were used in each experiment. The cerebellum and the anterior third of the cerebrum were removed to enrich for areas expressing $\mathrm{M}-\mathrm{RdgB} 2$. Tissues were homogenized in $1 \mathrm{ml}$ of extraction buffer (EB) (10 mM HEPES, $\mathrm{pH} 7.4,140 \mathrm{~mm}$ KOAc, $1 \mathrm{~mm} \mathrm{MgCl}_{2}, 0.1 \mathrm{~mm}$ EGTA, $1 \mathrm{~mm}$ DTT, $0.2 \mathrm{~mm}$ PMSF, $10 \mu \mathrm{g} / \mathrm{ml}$ trypsin inhibitor, $0.5 \mu \mathrm{g} / \mathrm{ml}$ leupeptin, and $5 \mu \mathrm{g} / \mathrm{ml}$ chymostatin) using a motor-driven homogenizer. Nuclei were pelleted at $2000 \times g$ for $10 \mathrm{~min}$. The postnuclear supernatant was divided into equal aliquots and centrifuged at $170,000 \times g$ for $40 \mathrm{~min}$ in a Beckman TL-100 ultracentrif uge. The supernatants were combined, and the pellets were resuspended in one of the following solutions: $\mathrm{NaCl}$ (EB plus $1 \mathrm{M} \mathrm{NaCl}), \mathrm{Na}_{2} \mathrm{CO}_{3}\left(0.2 \mathrm{M} \mathrm{Na}_{2} \mathrm{CO}_{3}, \mathrm{pH} 11\right.$, plus protease inhibitors as in EB), Triton (EB plus $2 \%$ Triton $\mathrm{X}-100$ ), Triton plus $\mathrm{NaCl}$ (EB plus $2 \%$ Triton $\mathrm{X}-100$ plus $1 \mathrm{M} \mathrm{NaCl}$ ), Urea (EB plus $5 \mathrm{M}$ urea), or Guanidine (6 M guanidine chloride). The samples were incubated for 40 min at $4^{\circ} \mathrm{C}$. After incubation, the guanidine extraction was diluted to $3 \mathrm{M}$. All the samples were centrifuged again at $170,000 \times g$ for $40 \mathrm{~min}$ in a Beckman TL-100 ultracentrifuge. Supernatants were collected separately, dialyzed against water overnight, and lyophilized. Supernatant or pellet proteins were solubilized in $70 \mu \mathrm{l}$ of protein loading buffer $(20 \mathrm{~mm}$ Tris, pH 6.8, 1\% SDS, 2 mM DTT, and 10\% glycerol) and boiled for 5 min, and $7 \mu \mathrm{l}$ of each sample was analyzed by immunoblotting. Sucrose density centrif ugation was performed as described previously (Parkin et al., 1999) with minor modifications. Briefly, one mouse cerebrum was mechanically homogenized and sonicated, and the postnuclear supernatant was centrifuged at $100,000 \times g$ for $90 \mathrm{~min}$ in a Beckman SW50.1 rotor. The pellet was resuspended by sonication in $0.6 \mathrm{ml}$ of $10 \mathrm{~mm}$ phosphate buffer containing $2 \%$ Triton X-100 and left at $4^{\circ} \mathrm{C}$ for $2 \mathrm{hr}$, and $0.5 \mathrm{ml}$ of this suspension was mixed with $0.5 \mathrm{ml}$ of $80 \%$ sucrose prepared in the same phosphate buffer. The sample was loaded at the bottom of a $5 \mathrm{ml}$ centrifuge tube and layered with $2 \mathrm{ml}$ of $30 \%$ sucrose and $2 \mathrm{ml}$ of $5 \%$ sucrose sequentially on top. Centrifugation was performed at $100,000 \times g$ for $22 \mathrm{hr}$. Seven fractions of $\sim 0.7 \mathrm{ml}$ each was collected from the top. Proteins from each supernatant fraction were recovered by precipitation with $10 \%$ trichloroacetic acid. Proteins recovered from each fraction were resuspended in $200 \mu \mathrm{l}$ of SDS protein sample buffer, and 10 $\mu l$ of each sample was loaded for immunoblot analysis.

Mouse immunoblot analysis. Samples were separated on $6 \%$ SDSpolyacrylamide gels and electroblotted to polyvinylidene difluoride membranes. Membranes were blocked in 5\% BSA-PBS for $1 \mathrm{hr}$ and incubated with either the a 2 or a 3 primary antibodies (1:4000) for $3 \mathrm{hr}$ at room temperature or overnight at $4^{\circ} \mathrm{C}$. Antibodies against synaptotagmin or actin (Sigma, St. Louis, MO) were included as controls. Antibody against caveolin-1 was purchased from Santa Cruz Biotechnology (Santa Cruz, CA). Antiserum against flotillin (Bickel et al., 1997) was a gift from Dr. Perry Bickel (Washington University, St. Louis, MO). The proteinantibody complex was detected with peroxidase-conjugated secondary antibodies (Calbiochem-Novabiochem International, La Jolla, CA) followed by chemiluminescent exposures (SuperSignal Substrate; Pierce) on Biomax ML film (Eastman Kodak, Rochester, NY).

Germline transformation of Drosophila. The $m-r d g B 2$ cDNA (cDNA clone 11-6) was placed downstream of the Drosophila R1-6 opsin (ninaE) promoter (Chang et al., 1997), followed by subcloning into the P-element transformation vector pCaSpeR-4 (Ashburner, 1989) to generate the transformation construct $\mathrm{P}[m-r d g B 2]$. Plasmid DNA (Wizard Midiprep; Promega, Madison, WI) was coinjected with $\Delta 2-3$ helper DNA into $w^{1118}$ embryos (Ashburner, 1989). Three independent insertion lines were phenotypically characterized. All three lines suppressed the $r d g B$ retinal degeneration phenotype. Based on its greater eye color intensity, line 21-2 was chosen for more detailed analysis. 


\begin{abstract}
M-RAgB2 M. I IKEYR IPLPMTVDEYR I AQLYMIQKKSRNE THGQGSGVE I LENRPY TDGPGGSGOY THKVYHVGMHIPGNFRS I LPKAALRVVEESWNAYPY TR TRF M-RAgB1 M. LIKEYH ILLPMS LDEYQVAQLYMIOKKSREESSGEGSGVE I LANRPY TDGPGGNGQY THKVYHVGSH IPGNFRALLPKAALQVEEESWNAYPY TRTRY

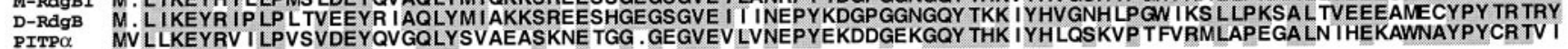

M-RAgB2 TCPFV.EKFSIDIETFYKTDTGENNNV FNLSPVEKSQLITDIIDIV.KDPVPPSEYKTEEDPKLFOSVKTCRGP LSENW IOEYKKR ..........LLPI 18

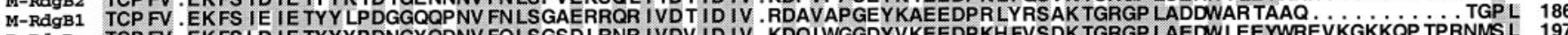
D-RAgB TCP FV . EKFSLD IE TYYYPDNGYQDNV FQLSGSDLRNR IVDV ID IV. KDQLWGGDYVKEEDPKHFVSDK TGRGP LAEDWLEEYWREVKGKKQP TPRNMSL 197 PITPQ TNEYMKEDFLIKIE TWHKPDLGTQENVHKLEPEAWKHVEA IY ID IADRSQV LSKDYKAEEDPAKFKS IKTGRGP LGP NWKQELVNQ......... KDCPY 190

M-RdgB2 MCAYKLCKVE FRYWGMOSK IERFIHDTGLRRVMVRAHROAWCWODEWYGLTMEK IRELEREVQLMLSRKMAQFSE. EGPSELS. KDSATKDQASGTTS 283 M-RAgB1 MCAYKLCKVE FRWWMQAK IEQF I HDVGLRRVMLRAHRQAWCWODEW IELSMAD IRALEEE TARMLAQRMAKCNTGSEGPEAQTPGKSS TEARPGTS TAG 286 D-RAgB MTAYK ICRVE FRYWGMQTKLEKF IHDVALRKMMLRAHRQAWAWODEWFGLTIED IRE LERQTQLALAKKMGGGEECSDSVSEPYV. .S TAA TAAS TTGS 295 D-RdgB MTA
PITP

M-RAgB2 DPGSKNGE .P. $\ldots \ldots \ldots \ldots \ldots \ldots \ldots \ldots \ldots \ldots \ldots \ldots \ldots \ldots$ LGRGKKOWS TSSKSSRS $\ldots \ldots$ SKRGASPSR $\ldots \ldots \ldots$ ISEWRMOSI 330 M-RAgB1 TPDGPEA PPGPDAS. D-RdgB ERKKSAPAVPP IV TQQPPSAEASSDEEGEEEEDDDEDENDA GGG M-RAgB1 ARDSENSSEEE FFDAHEGFSDSDEV FPKEMTKWNSNDFIDAFA.SP TEVEGVPDP TVMA TKG ................ IEDGARAPRDSEGLDGAGDLVVEA 423

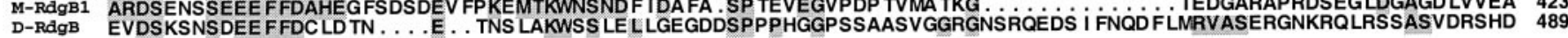

M-RAgB2 PSK . . . . . IHVLLLVLHGGTILDTGAGDPSKOGDTNT I TNV FDTVMRVHYPSALGHLAIRLVPCPP ICADAFALVSNLSPYGHDEGCLSSSOD. 504 M-RAgB1 CS ......... VHALFLI LHSGS I LDSGPGDTNSKQADVQTLS TAFEAV TRVHFPEALGHVALRLVPCPP ICAAAYALVSNLSPYSHDGDSLSRSOD D-RdgB SSPPGSPS TPSCPTTILILVVHAGSVLDAAS. ELTAKKSDV TTFRG FEAVMRHDYPS LLTHV TIKMVPCPS ICTDALGILSS LSPYS FDASPSAAD IPN 588 M-RAgB2 . .HIPLAALPLLATSSPQYQEAVATV IQRANLAYGDF IKSQEGV TFNGQVCLIIGDCVGG ILAFDALCYSGQPVSESQSSSRRGSVVSMQDADLLSPGTLA 602

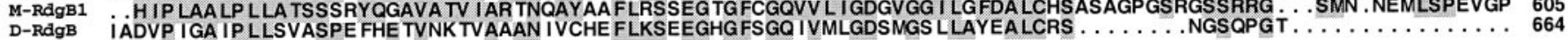
M-RAgB2 NAAHCSGGSGGGGSGGSS LESSRHLSRSN ID IPRSNGTEDSRRQLPRKRSDSS TYELDT IQQHQAFLSS LHASVLRNEPSSRRSSSS TMLDGAGALGKFD 702

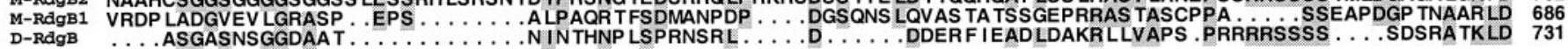
M-RAgB2 FEIADLFLFGCPLGLVLALRKTV IPS LDVFQLRPACQQVYNLFHPADPSASRLEPLLERRFHSLPP FS IPRYQRYPLGDGCS TLLADVLQTHNTV FQEHA 802 M-RdgB1 FEVSGFLFCLLLARK TVMPALVAOLPACEOIYNLFHADPCASRLEP LLAPKFQA IAP LAVPRYOK FP LGDGSSLLLADTLQTHSSLFLEEL 786 D-RAgB FEVCDFFMFGS LSVVLAARK. . LHDAKAALPRPNCHQVYNLFHPTDP IASRLEPLLSARFS I LAPVNVPRYAKYPLGNGQP LHLLEV IQSHPQRFNDGN 829

M-RAgB2 APSSPGTAPAGRG FRRASE IS IASQVSGMAESY TASSIAQIAAKWWGQKR IDYALYCPDALTAFP TVALPHLFHASYWES TDVVSFLLRQVMRHD.SSS I 901 M-RdgB1
D-RAgB

M-RdgB2 LELDKEVSVFTPSOPRERNORKRTHVKIRNVAANHRINDAVANEDGPOVVTGRFMYGPIDMNTLTGEKVDVHIMTOPPSGEWLHLDTLVTNSSGRVSYT 1001 M-RdgB2 LELDGKEVSV FTPSOPRERWORKR THVKLRNVAANHR INDAVANEDGPQVV TGRFMYGP LDMVTLTGEKVDVHYMTOP LSGKW IHFGTEV TNSSGR LTFP 983

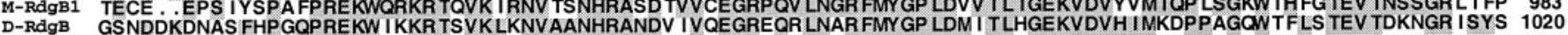

M-RAgB2 IPE THRLGVGVYP I KMVVRGDHTFADSY I TV LPRGTEFVV FS IDGS FAASVS IMGSDPKVRAGAVDVVRHWODLGYLI IYV TGRPDMOKORVVAWLAQHN 1101 M-RdgB1 VPSERALG I GVYPVRMVVRGDHTYAECCLTVVSRGTEAVVFS IDGS FTASVS IMGSDPKVRAGAVDVVRHWQDSGYLIVYV TGRPDMOKHRVVAWLSQHN 1083 D-RdgB IPDQVS LGYG IYPVKMVVRGDH TSVDCYMAVVPP LTECVV FS IDGS FTASNSV TGRDPKVRAGAVDVCRHWQE LGY LLIYITGRPDMOQRRVVSWLSQHN 1120

M-RAgB2 FPHGVVSFCDGLVHDP LRHKANFLKLLIISELHLRAHAAYGS TKDVAVYNS IS LSPMHIY IVGRP TKKLQQQCQF I TDGYAAHLAQLKYNHRARPARNTAT 1201 M-RdgB1 FPHGVVSFCDGLTHDP LRQKAMFLQS LVOEVELN IVAGYGSPKDVAVYAALGLSPSQTY IVGRAVRKLQAOCQFLSDGYVAHLGQLEAGSHSHAP.SGPP 1182 D-RdgB FPHGL IS FADGLS TDP LGHKTAYLNNLVQNHG IS I TAAYGSSKD ISVY TNVGMRTDQI FIVGKVGKKLQSNATV LSDGYAALAGLQAVGGSPA.KGNA 1219

M-RAgB2 RMALRKGSFGLPGQSDFLRSRNHLLRT ISAQPSGPSHRHDRTQTQMDSEQRGQRSMSVAASCWGRAMAGRLEPGAATGPK 1281

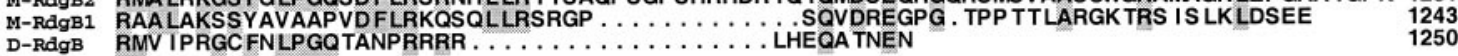

Figure 1. Amino acid sequence alignment of M-RdgB1,M-RdgB2, D-RdgB, and rat brain PITP $\alpha$. Identical residues are highlighted. Alignment was performed using MacVector 6.0 (Oxford Molecular Group, Oxford, UK) with manual adjustment. The complete $m$-rdgB2 cDNA sequence is available from GenBank (accession number AF058693).

Drosophila immunoblot analysis. Five fly heads of each genotype (Oregon R, $r d g B 2$, or $r d g B 2$; $\mathrm{P}[m-r d g B 2]$ ) were homogenized in $40 \mu \mathrm{l}$ of extraction buffer (62.5 mM Tris-HCl, pH 6.8, 2.3\% SDS, 1 mM EGTA, 1 mM DTT, and $0.01 \%$ bromophenol blue), boiled for $3 \mathrm{~min}$, and microcentrifuged for $1 \mathrm{~min}$. Eight microliters of supernatant was electrophoresed through a $10 \%$ SDS-PAGE and electroblotted to nitrocellulose (15 $\mathrm{V}$; $60 \mathrm{~min}$ ). The membranes were blocked for $60 \mathrm{~min}$ at room temperature using $5 \%$ nonfat dry milk in TTBS (TBS, pH 7.4, and $0.05 \%$ Tween 20 ), briefly rinsed in TTBS, and incubated overnight at room temperature with either anti-M-RdgB2 a2 antibodies $(1: 10,000$ in TTBS) or anti-Drosophila $\mathrm{RdgB}$ (D-RdgB) hybridoma supernatant (1:100). Membranes were washed in TTBS (three times in $10 \mathrm{~min}$ ), incubated in appropriate HRP-conjugated secondary antibody (sheep anti-chicken, $1: 15,000$ or donkey anti-mouse, 1:3000) for $60 \mathrm{~min}$, and then washed as described above. Chemiluminescent exposures (Amersham, Arlington Heights, IL) ranged from $30 \mathrm{sec}$ to $2 \mathrm{~min}$.

Electroretinography. ERGs were performed on newly eclosed flies as described (Zars and Hyde, 1996). Flies were dark adapted for at least 4 min before stimulation with white light $\left(1.2 \times 10^{-3} \mathrm{~W} / \mathrm{cm}^{2}\right)$. At least five different flies of each genotype were recorded.

Histology of Drosophila retina. Control and experimental flies were raised in a $12 \mathrm{hr}$ light/dark cycle for the desired time period and decapitated, the proboscis was removed, and the heads were fixed and processed into Polybed 812 for plastic sections as described previously (Chang et al., 1997). One micrometer sections were stained with $1 \%$ methylene blue $-1 \%$ azure II.

\section{RESULTS}

$m-r d g B 2$ is a novel mammalian homolog of Drosophila rdgB

We screened our mouse retinal cDNA library with a probe corresponding to the human $r d g B$ PITP domain and identified two classes of clones. One class represents the previously identified mouse $r d g B$ homolog. Although the open reading frame of our cDNA encodes an additional 184 amino acids at the C terminus than that published by one group (Chang et al., 1997), it is identical to the cDNA sequence reported by others (Aikawa et al., 1997; Rubboli et al., 1997). The second class of cDNA clones is derived from a novel gene. The full-length transcript is $\sim 7.6 \mathrm{~kb}$ and contains an open reading frame of 1281 amino acids. The predicted protein shares 46 and $56 \%$ amino acid identity over its entire length with $\mathrm{D}-\mathrm{RdgB}$ and the previously published mammalian RdgB, respectively (Fig. 1). The conceptually translated protein contains several common features of invertebrate and vertebrate $\mathrm{RdgB}$ proteins, such as a highly conserved $\mathrm{N}$-terminal PITP domain (amino acids 1-271; 46\% identity to rat PITP $\alpha$ ) (Fig. 1) and five hydrophobic segments that could represent membrane spanning regions. Therefore, this novel gene repre- 


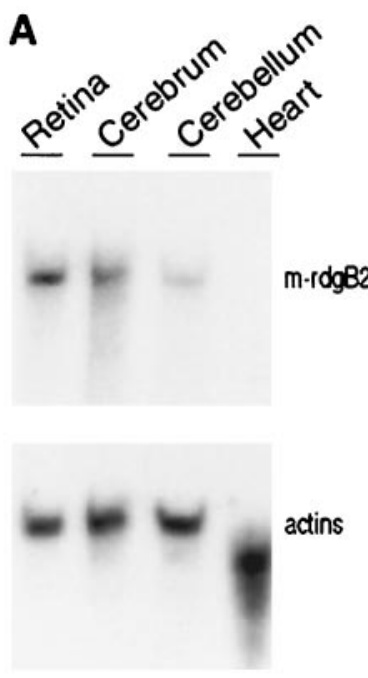

B
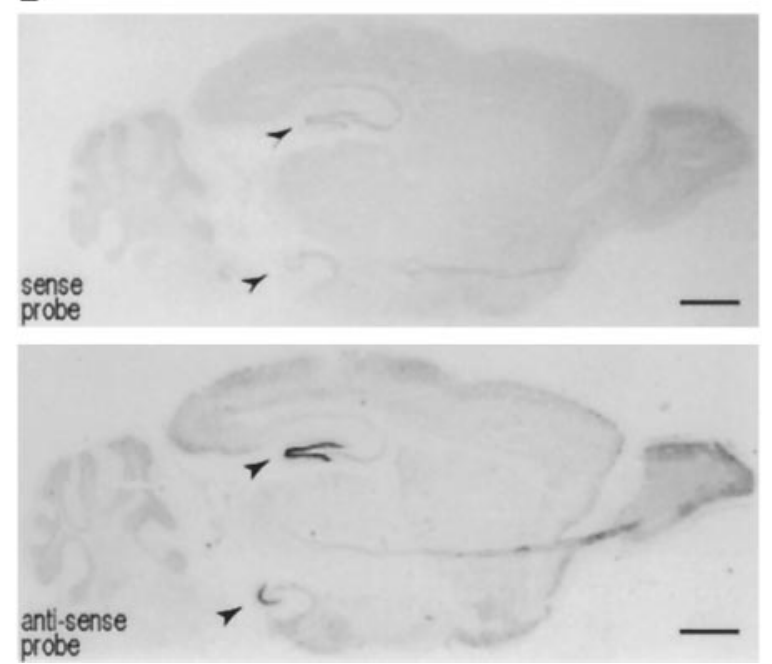

C
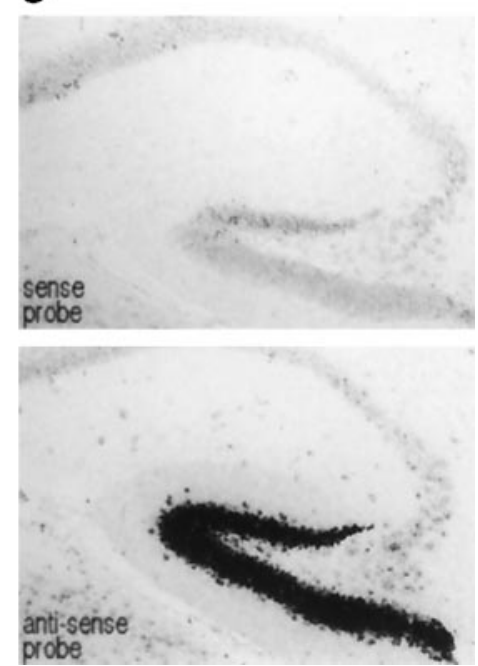

Figure 2. Tissue expression patterns of $m-r d g B 2$ by RNA analysis. $A$, Northern blot analysis with a $m$-rdgB2 probe. Retina and cerebrum showed a prominent band at $\sim 7.6 \mathrm{~kb}$, and cerebellum showed a weak signal of the same size. The blot was stripped and probed again with a labeled mouse $\beta$-actin cDNA to control for equivalency of loading. Heart has predominantly $\alpha$-actin (with a lower molecular weight), which cross-hybridized with the $\beta$-actin probe. $B$, Sagittal sections of mouse brain after in situ hybridization with sense (negative control; top) and antisense (bottom) m-rdgB2 probes. Arrowheads point to areas encompassing the hippocampal formation. Scale bar, $1 \mathrm{~mm}$. C, Higher magnification of the hippocampal formation after in situ hybridization as in $B$.

sents a second mammalian homolog of Drosophila $r d g B$, which we designate $m-r d g B 2$ (for mammalian $r d g B 2$ ) and refer to the previously published homolog as $m$-rdgB1.

A GenBank database search revealed extensive homology only with other mammalian PITPs, whereas a search of Expressed Sequence Tag databases identified only sequences matching $m$-rdgB1. Interestingly, we identified a domain of limited homology (amino acids 702-774) with a phosphatidic acid-preferring phospholipase Al, as well as three other putative phospholipases from Caenorhabditis elegans, enzymes presumably involved in phospholipid signaling (Higgs et al., 1998). Similar homology also exists between this phospholipase and the other known RdgB proteins. A motif search against the PROSITE database yielded an RGD sequence at amino acids 1020-1022, indicating the potential to interact with integrins. There is also a region (amino acids 1205-1226) that matches the leucine zipper repeat pattern, although this region was predicted to have a low probability of being in a coiled coil conformation by a 2ZIP program (Bornberg-Bauer et al., 1998).

\section{Neural $m-r d g B 2$ expression is restricted to the retina and dentate gyrus}

To determine the full extent of $m-r d g B 2$ expression in the mouse, we performed mRNA hybridization studies (Fig. 2), immunoblot analyses (Fig. 3), and tissue immunolocalization experiments (Fig. 4). These experiments demonstrated a highly restricted pattern of expression for $m-r d g B 2$, primarily confined to the retina and brain. The $m-r d g B 2$ transcript was readily detected in the retina and cerebrum, with lower levels in cerebellum (Fig. $2 A$ ). Although a multiple tissue RNA blot detected $m$-rdgB2 transcript in testis, it failed to detect $m-r d g B 2$ gene expression in the kidney, lungs, liver, skeletal muscle, or spleen (data not shown).

Polyclonal antibodies generated against two different regions of the M-RdgB2 protein (a2 and a3; see Materials and Methods) each detected a single $147 \mathrm{kDa}$ polypeptide on SDS-

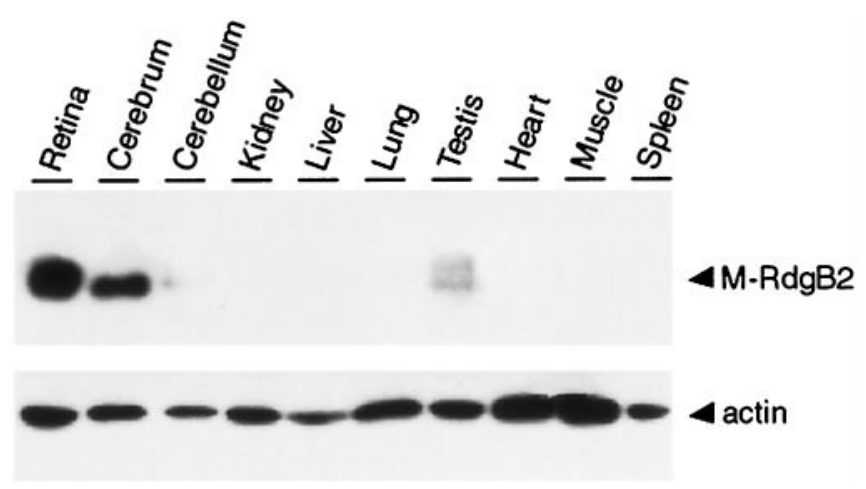

Figure 3. Immunoblot analysis of multiple tissue homogenates probed with $\mathrm{M}-\mathrm{RdgB} 2$ antibodies (a3). M-RdgB2 is found at high levels in the retina and cerebrum and at a lower level in the testis. An anti-actin antibody was included to control for loading.

polyacrylamide gels (Fig. 3). Consistent with the RNA analysis, M-RdgB2 possessed a highly restricted tissue expression pattern (Fig. 3). For example, high M-RdgB2 levels were detected in the retina and the cerebrum, whereas lower levels were observed in testis. Although $m-r d g B 2$ transcript was found in the cerebellum, $\mathrm{M}-\mathrm{RdgB} 2$ protein in this brain region was only marginally detectable.

We examined M-RdgB2 protein localization in the retina by immunocytochemistry. The M-RdgB2 protein was localized by fluorescence microscopy to the inner layers of the retina, including the inner nuclear layer and both synaptic layers with lower levels of signal in the photoreceptor inner segments (Fig. 4A). Consistent with this localization, $m-r d g B 2$ transcript was detected in all the retinal layers (data not shown). In contrast, $m$-rdgB1 mRNA and protein were predominantly detected in the photoreceptor inner segments and inner nuclear layer (Chang et al., 1997). 

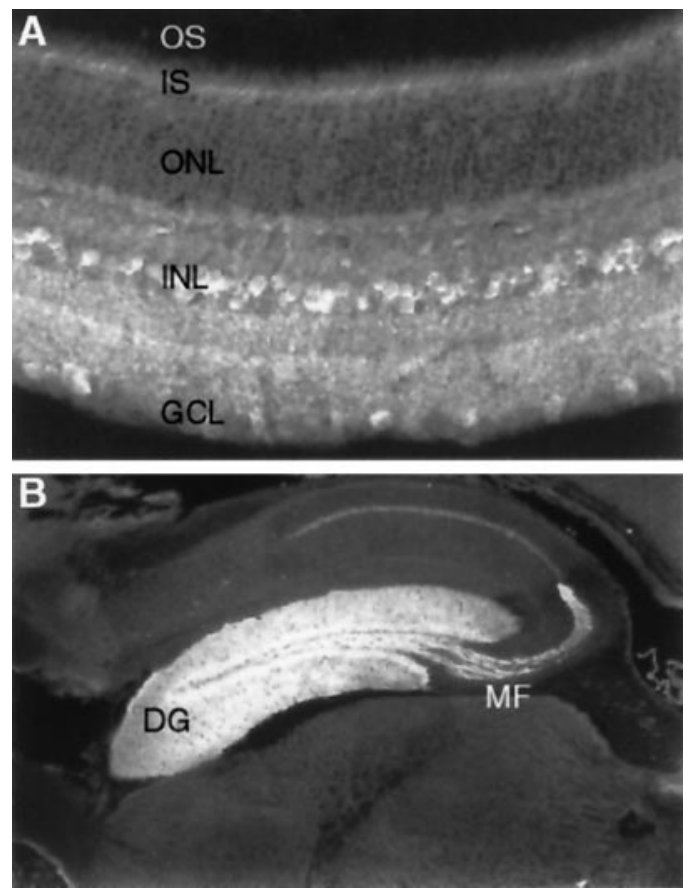

Figure 4. Immunocytochemistry of retina and brain sections, stained with M-RdgB2 antibodies (a3). A, Retina. OS, Outer segments; $I S$, inner segments; $O N L$, outer nuclear layer; $I N L$, inner nuclear layer; $G C L$, ganglion cell layer. $B$, Hippocampus in a transverse section of mouse brain. $D G$, Dentate gyrus; $M F$, mossy fibers.

The $m-r d g B 2$ gene exhibits a highly restricted pattern of expression in the brain unlike its generalized retinal expression pattern. In situ hybridization revealed that $m-r d g B 2$ expression was predominantly localized to the dentate gyrus; we did not detect $m-r d g B 2$ mRNA in other regions of the hippocampus (field CA1-CA3) (Fig. 2B,C). All other areas of the brain were either negative for the transcript or stained only slightly above background relative to the sense probe control. This was in contrast to $m$-rdgB1, which exhibited diff use expression throughout the brain (data not shown). Immunocytochemistry with the M-RdgB2specific antibodies was consistent with the in situ hybridization pattern. On whole-brain sections, the dentate gyrus was prominently stained, including both the mossy fibers (axons) and the molecular layer dendritic field (Fig. 4B). In other areas of the brain, only the caudate putamen exhibited weak staining with the M-RdgB2 antibody. Thus, the higher level of M-RdgB2 in cerebrum relative to cerebellum could be attributed to the very high dentate gyrus expression.

\section{M-RdgB2 is likely associated with the cytoskeleton}

$\mathrm{M}-\mathrm{RdgB} 2$, as well as $\mathrm{D}-\mathrm{RdgB}$ and $\mathrm{M}-\mathrm{RdgB} 1$, possess multiple hydrophobic segments downstream from the PITP domain that could act as membrane spanning segments. To investigate whether $\mathrm{M}-\mathrm{RdgB} 2$ is an integral membrane protein, we performed subcellular fractionation studies. Although M-RdgB2 was associated with the high-speed pellet, it did not behave as an integral membrane protein (Fig. 5). Conditions that disrupt protein-protein interactions, such as $1 \mathrm{M} \mathrm{NaCl}$, high $\mathrm{pH}$, or strong denaturants, solubilized $\mathrm{M}-\mathrm{RdgB} 2$ partially or completely. In contrast, the detergent Triton X-100 failed to solubilize any $\mathrm{M}-\mathrm{RdgB} 2$. This extraction pattern is completely opposite that of an integral membrane protein marker synaptotagmin (Fig. 5A). M-RdgB2 was not solubilized by either $2 \%$ CHAPS, Triton X-100 at $37^{\circ} \mathrm{C}$, or a combination of $2 \%$ Triton $\mathrm{X}-100$ and $0.5 \%$ saponin (data not shown), suggesting it is not associated with a "rafts"-like membrane structure or Triton-insoluble membrane microdomains (Simons and Ikonen, 1997). This was further supported by separating tissue homogenates on a sucrose equilibrium density gradient before immunoblot analysis. In these experiments (Fig. $5 B)$, Triton-insoluble membranes were found concentrated in fraction 4 , as indicated by the presence of a light scattering band and confirmed by the presence of two proteins known to be enriched in Triton-insoluble membranes, flotillin (Bickel et al., 1997), and caveolin-1 (Parton, 1996). M-RdgB2 was present only in the pellet fraction. Therefore, $\mathrm{M}-\mathrm{RdgB} 2$ is not an integral membrane protein but is associated in vivo with a large protein complex likely to be the cytoskeleton.

\section{$m-r d g B 2$ maps to a syntenic region that contains loci associated with retinitis pigmentosa and autism}

We mapped the chromosomal location of the mouse $m$-rdgB2 gene using gene polymorphisms across strains and analyzing the

\begin{tabular}{|c|c|c|c|c|c|c|c|c|c|c|}
\hline \multicolumn{7}{|c|}{ Brain } & \multicolumn{4}{|c|}{ Retina } \\
\hline 思 & $\begin{array}{l}\bar{\Phi} \\
\text { Z }\end{array}$ & $\begin{array}{l}\text { ర్ } \\
\text { בึ } \\
\text { z }\end{array}$ & $\stackrel{8}{8}$ & 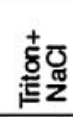 & ळ & 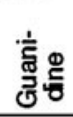 & 田 & $\begin{array}{l}\text { ర్ల్ } \\
\text { జֶ }\end{array}$ & 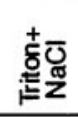 & 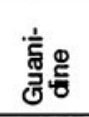 \\
\hline$S \quad P$ & $S \quad P$ & $S P$ & $S \quad P$ & $S \quad P$ & $S \quad P$ & $S \quad P$ & $S \quad P$ & $S \quad F$ & $\mathrm{SP}$ & $S \quad P$ \\
\hline
\end{tabular}

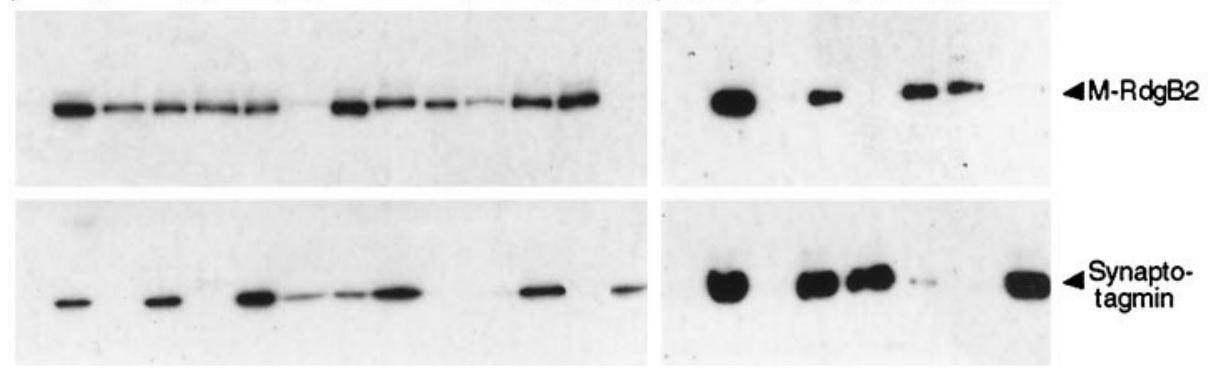

$1 \underline{2} \underline{3} \underline{4} \underline{4} \underline{5} \underline{6} \underline{7} \underline{8}$

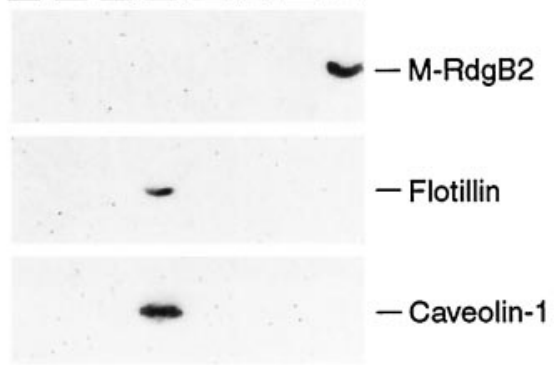

Figure 5. Subcellular fractionation of brain and retina M-RdgB2 detected by immunoblotting. $A$, High-speed pellets from tissue homogenates were extracted with a variety of conditions as indicated. See Materials and Methods for concentrations of reagents. $S$, Supernatant; $P$, pellet. The integral membrane protein synaptotagmin was included as an indicator of membrane solubilization. $B$, Immunoblot analysis of Triton-insoluble materials from mouse brain homogenate after sucrose equilibrium density centrif ugation. Fraction numbers are in the order of increasing densities. 8 is the pellet. Two marker proteins known to be associated with Triton-insoluble membranes are found in fraction 4, whereas M-RdgB2 is present exclusively in the pellet. 

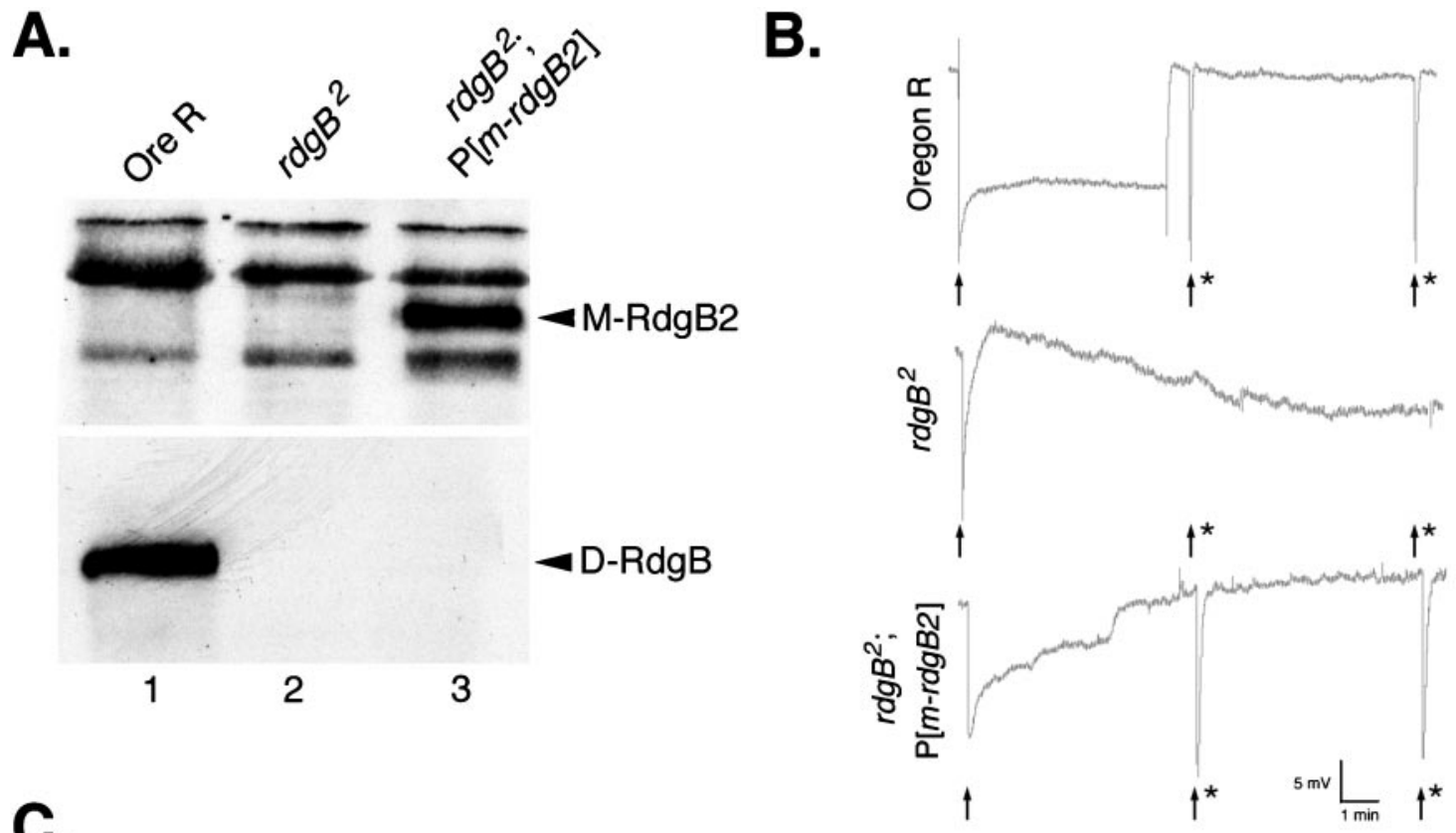

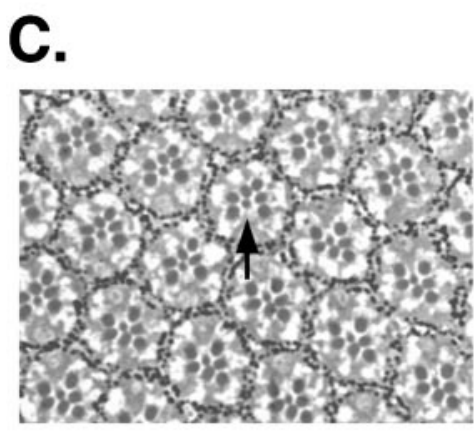

Oregon R

(7 days)

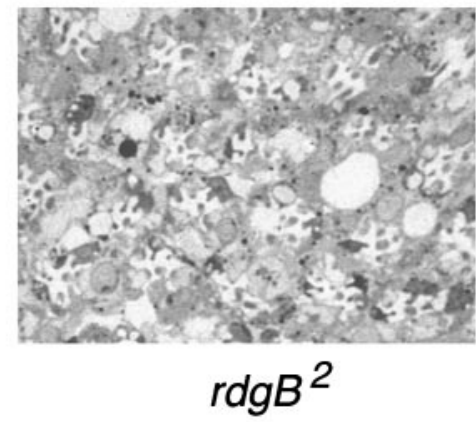

(7 days)

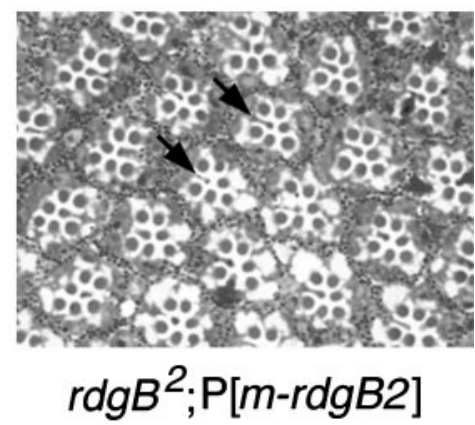

(8 days)

Figure 6. Transgenic suppression of Drosophila $r d g B$ mutant phenotypes by M-RdgB2. $A$, The immunoblot analysis was performed using head protein extract from wild-type (Oregon R), $r d g B 2$ null mutants $(r d g B 2$ ), or $r d g B 2$ transgenic flies expressing the M-RdgB2 protein. M-RdgB2 was expressed in the transgenic flies only (top plot). The bottom plot, probed with anti-Drosophila RdgB, confirms that Drosophila RdgB protein is not expressed in the transgenic $r d g B 2$; $\mathrm{P}[m-r d g B 2]$ flies. $B$, ERG traces from newly eclosed, dark-adapted wild-type (Oregon $\mathrm{R}$ ), $r d g B 2$ null mutants ( $r d g B 2$ ), and $r d g B 2$ transgenic flies expressing the M-RdgB2 protein ( $r d g B 2 ; \mathrm{P}[m-r d g B 2])$. The flies were stimulated with 5 min of constant saturating light, followed by 30 sec dark adaptation, $2 \mathrm{sec}$ light stimulus, 5 min dark adaptation, and then another $2 \mathrm{sec}$ light stimulus. The initiation of the 5 min and 2 sec light stimuli are marked with an arrow and an arrow with asterisk, respectively. A $5 \mathrm{mV}$ and 1 min scale are shown. $C$, Histological sections from wild-type, rdgB2, and $r d g B 2 ; \mathrm{P}[m-r d g B 2]$ flies aged in $12 \mathrm{hr}$ light/dark conditions. The $r d g B 2$ retina at $7 \mathrm{~d}$ of age shows severe retinal degeneration, whereas the $r d g B 2$; $\mathrm{P}[m-r d g B 2]$ retina at $8 \mathrm{~d}$ of age is nearly like wild-type (Oregon $\mathrm{R})$. The arrows point to $\mathrm{R} 7 \mathrm{cells}$, which are degenerating in the $r d g B 2 ; \mathrm{P}[m-r d g B 2]$ retinas.

segregation of a target gene against known markers in backcrossed progeny. Two interspecific backcross panels with 94 individual DNA samples in each panel were used. We determined that $m-r d g B 2$ is on the distal end of mouse chromosome 5. This chromosomal location is different from $m$-rdgB1, which was mapped to chromosome 19 (Chang et al., 1997). The order and recombination distances, expressed in centimorgans $(\mathrm{cM} \pm \mathrm{SE}$, $>95 \%$ confidence), are D5Mit188, $1.59 \pm 0.91$; D5Mit95, $0.53 \pm$ $0.53 ; m-r d g B 2,10.64 \pm 2.25 ; A z g p 1$, Epo-distal. The interval between D5Mit25 and Azgpl is syntenic to human chromosome $7 \mathrm{p} 12-\mathrm{q} 22$ in which one form of retinitis pigmentosa and autism were mapped (http://www.ncbi.nlm.nih.gov/htbin-post/Omim/ getmap?d1924).

\section{Transgenic expression of M-RdgB2 partially rescues the Drosophila rdgB mutant phenotypes}

To begin defining the function of $\mathrm{M}-\mathrm{RdgB} 2$ in vivo, we expressed the $m-r d g B 2$ cDNA in $r d g B 2$ null mutant flies. We confirmed that the M-RdgB2 protein was expressed in $r d g B 2$; $\mathrm{P}[m-r d g B 2]$ transgenic flies by immunoblots (Fig. 6A). The M-RdgB2 a 2 antibodies detected the correct size protein in transgenic flies and did not cross-react with the Drosophila RdgB protein (Oregon R flies). The ERG light response of the transgenic flies was compared with both wild-type (Oregon R) and $r d g B 2$ mutant flies (Fig. 6B). The ERG measures the sum electrical potential of the retina in response to a light stimulus. Newly eclosed flies that were raised in constant darkness were recorded during a 5 min saturating light stimulus, $30 \mathrm{sec}$ of dark recovery, a $2 \mathrm{sec}$ light stimulus, 5 min of dark recovery, and a final $2 \mathrm{sec}$ light stimulus. Wild-type flies exhibited a $25 \mathrm{mV}$ light response amplitude that was maintained for the entire initial 5 min stimulus, and $<30$ sec of dark recovery was required to reproduce a $25 \mathrm{mV}$ light response amplitude (Fig. $6 B$ ). Although the $r d g B 2$ mutant also possessed a $25 \mathrm{mV}$ response amplitude to the first light stimulus, it could not be maintained for the entire $5 \mathrm{~min}$ stimulation (Fig. $6 B$ ). Furthermore, the $r d g B 2$ 
mutant did not recover a significant light response, even after 5 min of dark recovery. Previously, we demonstrated that the $\operatorname{rdg} B 2$ mutant requires $>30$ min of dark recovery to regenerate the 25 $\mathrm{mV}$ response amplitude under this regimen (Milligan et al., 1997). Thus, the $r d g B$ mutant is defective in ERG light response maintenance and also in the dark recovery. In comparison, the $\operatorname{rdg} B 2$; $\mathrm{P}[m-r d g B 2]$ transgenic flies produced a $20 \mathrm{mV}$ light response amplitude to the first stimulus that was maintained for nearly all of the 5 min stimulation, although at a significantly reduced level relative to wild-type (Fig. $6 B$ ). Thus, a detectable ERG light response amplitude was present in the transgenic flies significantly longer than in the $r d g B 2$ mutants. Furthermore, in contrast to the $r d g B 2$ flies, the transgenic flies produced a full $25 \mathrm{mV}$ light response to the second light stimulus after only $30 \mathrm{sec}$ of dark recovery. Therefore, expression of $\mathrm{M}-\mathrm{RdgB} 2$ fully restored the rapid dark recovery to $r d g B 2$ mutant flies.

The transgenic flies were also examined for suppression of the $r d g B 2$-mediated retinal degeneration phenotype (Fig. $6 C$ ). At $8 \mathrm{~d}$ posteclosion, the retina of the $r d g B 2 ; \mathrm{P}[m-r d g B 2]$ transgenic flies lacked the massive photoreceptor cell loss and ommatidial disorganization that was observed in 7-d-old $r d g B 2$ null mutants. However, the retina of the transgenic flies possessed slightly smaller rhabdomeres and some disorganization, which were not apparent in the wild-type control. Degenerating R7 photoreceptors were apparent in the transgenic flies (Fig. 6C, arrows) because of $m$-rdgB2 expression being restricted to the R1-6 photoreceptors from the ninaE promotor (Milligan et al., 1997) The suppression of R1-6 degeneration is not complete, because 14$\mathrm{d}$-old transgenic flies begin to demonstrate the $r d g B 2$ degeneration phenotype (data not shown).

\section{DISCUSSION}

We identified a second mammalian $r d g B$ gene $(m-r d g B 2)$ that encodes a protein possessing $56 \%$ amino acid identity with that encoded by $m$-rdgB1. The $\mathrm{M}-\mathrm{RdgB} 2$ protein contains a PITP domain and several stretches of hydrophobic amino acids found in all previously reported $\mathrm{RdgB}$ family members. Analyses of the $\mathrm{M}-\mathrm{RdgB} 2$ neural expression pattern, $m-r d g B 2$ transgenic expression in $r d g B$ mutant flies, and subcellular fractionation suggest the two mammalian RdgB proteins likely mediate nonredundant functions. Recently, three human $r d g B$ homologs were identified by virtue of their ability to interact with the protein tyrosine kinase PYK2 (Lev et al., 1999). Based on protein sequence and chromosomal mapping, M-RdgB1 and M-RdgB2 are likely orthologs of the human Nir2 and Nir3 proteins, respectively. This raises the intriguing possibility that the $\mathrm{M}-\mathrm{RdgB}$ activity or its association with the cytoskeleton is regulated by phosphorylation.

$M-r d g B 2$ expression, determined at both the mRNA and protein level, is primarily limited to the retina and dentate gyrus of the brain. This differs from $m-r d g B 1$ expression in several respects. First, the relative expression levels of $\mathrm{M}-\mathrm{RdgB} 2$ and M-RdgB1 differ by retinal layer. Fluorescent immunolocalization results revealed that $\mathrm{M}-\mathrm{RdgB} 2$ is expressed at highest levels in the inner retina, whereas $\mathrm{M}-\mathrm{RdgB} 1$ protein expression is more prominent in the photoreceptor layer (Chang et al., 1997). Second, the brain expression pattern of $m-r d g B 2$ differs from the expression pattern of $m$-rdgB1. Based on in situ mRNA hybridization, $m-r d g B 2$ expression is primarily restricted to the dentate gyrus, which is consistent with the immunolocalization of the M-RdgB2 protein. In contrast, in situ hybridization demonstrated that $m-r d g B 1$ transcript is expressed diffusely throughout the brain. Finally, using both Northern and immunoblot analysis, we did not detect $m-r d g B 2$ expression in most of the non-neural tissues we examined. Although $m-r d g B 1$ expression was detected in many non-neural tissues by some (Aikawa et al., 1997), others reported an expression pattern that was restricted to retina and brain (Chang et al., 1997). Therefore, the spatial expression patterns of $m$-rdgB1 and $m$-rdgB2 suggest the two mammalian RdgB proteins might perform different roles in the retina and that the M-RdgB2 protein may mediate specialized functions in the hippocampus as well.

The hippocampal formation has an important role in learning and memory, with the dentate gyrus being part of the trisynaptic pathway that relays information from the entorhinal cortex to the CA3 field of the hippocampus. A long-standing hypothesis is that synaptic plasticity and long-term potentiation (LTP) are the basis of learning and memory (Malenka, 1994). The mossy fiber LTP is both induced and expressed presynatptically, and is independent of NMDA receptors (Zalutsky and Nicoll, 1990). In sharp contrast, the LTP in the CA1 and CA3 regions of the hippocampus is both postsynaptic and NMDA receptor-dependent (Zalutsky and Nicoll, 1990). In this regard, it may be significant that dentate gyrus expresses $\mathrm{M}-\mathrm{RdgB} 2$, which is not detected in the other hippocampal regions. An analogous region of the Drosophila brain involved in sensory processing and learning is the mushroom bodies, which also exhibit relatively high levels of $\mathrm{RdgB}$ expression (Vihtelic et al., 1993).

Biochemical analysis of $\mathrm{M}-\mathrm{RdgB} 2$ indicates that the protein is likely associated with the cytoskeleton either directly or indirectly through protein-protein interactions. The original model for $\mathrm{D}-\mathrm{RdgB}$ existing as an integral membrane protein was based only on alkaline membrane extraction and the existence of six hydrophobic regions (Vihtelic et al., 1993). Parallel experiments using both retina and brain tissue indicated that $\mathrm{M}-\mathrm{RdgB} 2$ was solubilized from the particulate fraction after treatment with the strong denaturing agent guanidine chloride and not with detergents. Contrary to the previous model that the multiple hydrophobic domains identified in all $\mathrm{RdgB}$ proteins function to span cellular membrane, these data suggest the mammalian $\mathrm{RdgB}$ proteins do not assume an integral membrane topology. Our current data show that the $\operatorname{RdgB}$ protein is a component of a large protein complex.

Expression of the M-RdgB2 protein delayed $r d g B 2$-dependent retinal degeneration and partially restored the ERG light response to $r d g B 2$ null mutant flies but not to the same extent that M-RdgB1 expression rescued the $r d g B 2$ mutant phenotypes (Chang et al., 1997). It is unlikely that the differences in phenotypic rescue were because of expression levels of M-RdgB1 and M-RdgB2 because we tested multiple independent lines and examined flies that expressed one and two copies of each transgene. Thus, the difference between $\mathrm{M}-\mathrm{RdgB} 1$ and $\mathrm{M}-\mathrm{RdgB} 2$ in suppressing the $r d g B 2$ mutant phenotypes further suggests there are functional differences between the two mouse homologs and that $\mathrm{M}-\mathrm{RdgB} 1$ is functionally more similar to D-RdgB than M-RdgB2. Although the ERG phenotypes resulting from expression of either $\mathrm{M}-\mathrm{RdgB} 1$ or $\mathrm{M}-\mathrm{RdgB} 2$ can be compared, it is difficult to correlate their phenotypes to the molecular function of the two proteins because the ERG merely measures the voltage change across the entire retina and thus does not resolve changes at the single cell level. The functional conservation of the mammalian $\mathrm{RdgB}$ proteins in the Drosophila retina is not attributable entirely to the presence of a PITP domain because the rat brain PITP $\alpha$ failed to have any effect on the $r d g B 2$ mutant phenotypes (Milligan et al., 1997). We recently identified a zebrafish RdgB ho- 
molog that lacks the N-terminal PITP domain (pl-RdgB). Transgenic expression of $\mathrm{pl}-\mathrm{RdgB}$ in $r d g B 2$ mutant flies suppressed the retinal degeneration without restoring the mutant light response (V. A. Elagin, R. B. Elagina, C. J. Doro, T. S. Vihtelic, and D. R. Hyde, unpublished observations). This suggests that regions of the $\mathrm{RdgB}$ protein other than the PITP domain are functionally important in the Drosophila photoreceptor cell. Because both mouse proteins suppress the retinal degeneration and restore an electrophysiological light response, these essential functions must reside in both molecules and indicate that the functional differences may lie in regulation of protein activity.

PITPs are required in a number of cellular processes relying on phosphatidylinositol metabolites (for review, see Wirtz, 1997; Kearns et al., 1998; Wiedemann and Cockcroft, 1998). Based on kinetic studies, Cunningham et al. (1995) suggested the main function of PITPs is to present PI to lipid kinases for localized production of $\mathrm{PIP}_{2}$ for use as a signaling molecule or as a substrate for the generation of second messengers (Kearns et al., 1998; Wiedemann and Cockcroft, 1998). In contrast, others have shown that PITP is simply a passive transporter of PI down a chemical gradient from its site of synthesis to the site of consumption (Currie et al., 1997). Direct interactions between a PITP and multiple downstream enzymes are inconsistent with the finding that Sec14p, a yeast PITP that bears no homology to mammalian PITP, is equally effective in PI signaling reconstitution assays (Hay and Martin, 1993; Cunningham et al., 1995, 1996; Kearns et al., 1998). The inconsistency may be reconciled by considering the possibility that $\mathrm{RdgB}$ proteins function as intermediates between soluble PITPs and the localized regulation of polyphosphoinositide synthesis and cycling. An $\mathrm{RdgB}$ protein associated with either the membrane skeleton or internal cytoskeleton provides an excellent candidate to anchor localized production and consumption of PI signaling molecules for the tasks discussed above. Spatially restricted PI signaling may be a general mechanism for encoding spatial information in neurons (Finch and Augustine, 1998). However, it was demonstrated that expression of the N-terminal PITP domain of D-RdgB was sufficient to completely restore the wild-type phenotypes to $\mathrm{rdgB} 2$ null mutant flies (Milligan et al., 1997). This suggests that either the spatial restriction of $\mathrm{RdgB}$ in Drosophila photoreceptors is not critical or that the soluble RdgB-PITP domain possesses an unidentified mechanism for proper subcellular localization.

The initial characterization of $m-r d g B 2$ and its corresponding protein has allowed direct comparisons to the previously reported $m$-rdgB1, which demonstrated important differences between the two mammalian $r d g B$ homologs. These differences lie in their tissue expression specificities and their ability to functionally substitute in the Drosophila phototransduction cascade. Biochemical analysis by subcellular fractionation represents the first data indicating the $\mathrm{RdgB}$ proteins are not integral membrane proteins and opens speculation regarding the function of the multiple distinct hydrophobic domains. PI metabolism and signaling mediate a myriad of essential eukaryotic functions and, although the role of $\mathrm{RdgB}$ in retinal photoreceptor cells remains unclear, the cloning and characterization of two different mammalian $r d g B$ genes should make it possible to put hypotheses to direct tests.

\section{REFERENCES}

Aikawa Y, Hara H, Watanabe T (1997) Molecular cloning and characterization of mammalian homologues of the Drosophila retinal degeneration B gene. Biochem Biophys Res Commun 236:559-564.

Ashburner M (1989) Drosophila: a laboratory handbook. Cold Spring Harbor, NY: Cold Spring Harbor Laboratory.
Bankaitis VA, Aitken JR, Cleves AE, Dowhan W (1990) An essential role for a phospholipid transfer protein in yeast Golgi function. Nature 347:561-562.

Bickel PE, Scherer PE, Schnitzer JE, Oh P, Lisanti MP, Lodish HF (1997) Flotillin and epidermal surface antigen define a new family of caveolae-associated integral membrane proteins. J Biol Chem 272:13793-13802.

Bornberg-Bauer E, Rivals E, Vingron M (1998) Computational approaches to identify leucine zippers. Nucleic Acids Res 26:2740-2746.

Chang JT, Milligan S, Li Y, Chew CE, Wiggs J, Copeland NG, Jenkins NA, Campochiaro PA, Hyde DR, Zack DJ (1997) Mammalian homolog of Drosophila retinal degeneration B rescues the mutant fly phenotype. J Neurosci 17:5881-5890.

Cleves AE, McGee TP, Whitters EA, Champion KM, Aitken JR, Dowhan W, Goebl M, Bankaitis VA (1991) Mutations in the CDPcholine pathway for phospholipid biosynthesis bypass the requirement for an essential phospholipid transfer protein. Cell 64:789-800.

Cunningham E, Thomas GM, Ball A, Hiles I, Cockcroft S (1995) Phosphatidylinositol transfer protein dictates the rate of inositol trisphosphate production by promoting the synthesis of PIP2. Curr Biol 5:775-783.

Cunningham E, Tan SK, Swigart P, Hsuan J, Bankaitis V, Cockcroft S (1996) The yeast and mammalian isoforms of phosphatidylinositol transfer protein can all restore phospholipase C-mediated inositol lipid signaling in cytosol-depleted RBL-2H3 and HL-60 cells. Proc Natl Acad Sci USA 93:6589-6593.

Currie RA, MacLeod BM, Downes CP (1997) The lipid transfer activity of phosphatidylinositol transfer protein is sufficient to account for enhanced phospholipase $\mathrm{C}$ activity in turkey erythrocyte ghosts. Curr Biol 7:184-190.

Finch EA, Augustine GJ (1998) Local calcium signalling by inositol1,4,5-trisphosphate in Purkinje cell dentrites. Nature 396:753-756.

Guo J, Yu FX (1997) Cloning and characterization of human homologue of Drosophila retinal degeneration B: a candidate gene for degenerative retinal diseases. Dev Genet 20:235-245.

Harris WA, Stark WS (1977) Hereditary retinal degeneration in Drosophila melanogaster. A mutant defect associated with the phototransduction process. J Gen Physiol 69:261-291.

Hay JC, Martin TF (1993) Phosphatidylinositol transfer protein required for ATP-dependent priming of $\mathrm{Ca}(2+)$-activated secretion. Nature 366:572-575.

Heisenberg M (1971) Separation of receptor and lamina potentials in the electroretinogram of normal and mutant Drosophila. J Exp Biol 55:85-100.

Higgs HN, Han MH, Johnson GE, Glomset JA (1998) Cloning of a phosphatidic acid-preferring phospholipase A1 from bovine testis. J Biol Chem 273:5468-5477.

Hotta Y, Benzer S (1969) Abnormal electroretinograms in visual mutants of Drosophila. Nature 222:354-356.

Kearns BG, Alb Jr JG, Bankaitis V (1998) Phosphatidylinositol transfer proteins: the long and winding road to physiological function. Trends Cell Biol 8:276-282.

Lev S, Hernandez J, Martinez R, Chen A, Plowman G, Schlessinger J (1999) Identification of a novel family of targets of PYK2 related to Drosophila retinal degeneration B (rdgB) protein. Mol Cell Biol 19:2278-2288.

Malenka RC (1994) Synaptic plasticity in the hippocampus: LTP and LTD. Cell 78:535-538.

Milligan SC, Alb Jr JG, Elagina RB, Bankaitis VA, Hyde DR (1997) The phosphatidylinositol transfer protein domain of Drosophila retinal degeneration B protein is essential for photoreceptor cell survival and recovery from light stimulation. J Cell Biol 139:351-563.

Paetkau DW, Elagin VA, Sendi LM, Hyde DR (1999) Isolation and characterization of Drosophila retinal degeneration B suppressors. Genetics 151:713-724.

Pak WL, Grossfield J, Arnold KS (1970) Mutants of the visual pathway of Drosophila melanogaster. Nature 227:518-520.

Parkin ET, Hussain I, Karran EH, Turner AJ, Hooper NM (1999) Characterization of detergent-insoluble complexes containing the familial Alzheimer's disease-associated presenilins. J Neurochem 72:1534-1543.

Parton RG (1996) Caveolae and caveolins. Curr Opin Cell Biol 8:542-548.

Ranganathan R, Malicki DM, Zuker CS (1995) Signal transduction in Drosophila photoreceptors. Annu Rev Neurosci 18:283-317. 
Rowe LB, Nadeau JH, Turner R, Frankel WN, Letts VA, Eppig JT, Ko MS, Thurston SJ, Birkenmeier EH (1994) Maps from two interspecific backcross DNA panels available as a community genetic mapping resource. Mamm Genome [Erratum (1994) 5:463] 5:253-274.

Rubboli F, Bulfone A, Bogni S, Marchitiello A, Zollo M, Borsani G, Ballabio A, Banfi S (1997) A mammalian homologue of the Drosophila retinal degeneration $\mathrm{B}$ gene: implications for the evolution of phototransduction mechanisms. Genes Funct 1:205-213.

Simons K, Ikonen E (1997) Functional rafts in cell membranes. Nature 387:569-572.

Vihtelic TS, Hyde DR, O’Tousa JE (1991) Isolation and characterization of the Drosophila retinal degeneration B $(r d g B)$ gene. Genetics 127:761-768.
Vihtelic TS, Goebl M, Milligan S, O’Tousa JE, Hyde DR (1993) Localization of Drosophila retinal degeneration B, a membrane-associated phosphatidylinositol transfer protein. J Cell Biol 122:1013-1022.

Wiedemann C, Cockcroft S (1998) The role of phosphatidylinositol transfer proteins (PITPs) in intracellular signalling [review]. Trends Endocrinol Metab 9:324-328.

Wirtz KW (1991) Phospholipid transfer proteins. Annu Rev Biochem 60:73-99.

Wirtz KW (1997) Phospholipid transfer proteins revisited. Biochem J 324:353-360.

Zalutsky RA, Nicoll RA (1990) Comparison of two forms of long-term potentiation in single hippocampal neurons. Science 248:1619-1624.

Zars T, Hyde DR (1996) rdgE: a novel retinal degeneration mutation in Drosophila melanogaster. Genetics 144:127-138. 